\title{
The accuracy of SAPS II and SOFA score to predict mortality in immunosuppressed patients admitted in intensive care
}

\author{
PB Medeiros*, M Monteiro, T Cardoso, GC Campello \\ From ESICM LIVES 2015 \\ Berlin, Germany. 3-7 October 2015
}

\section{Introduction}

Immunosuppressed patients are a special group in intensive care (ICU), with predisposition to more serious illness. It is essential to accurately predict their clinical outcomes after admission in the ICU.

\section{Objectives}

To study independent risk factors associated with hospital mortality in immunosuppressed patients admitted into the ICU and to evaluate the accuracy of Simplified Acute Physiology Score (SAPS) II and Sequential Organ Failure Assessment (SOFA) scores to predict hospital mortality in this group.

\section{Methods}

Retrospective cohort study conducted in a mixed ICU of a tertiary care, university-affiliated hospital, including all immunosuppressed patients admitted between 2011 and 2014.

The association of the following variables with hospital mortality was studied through logistic regression models: sex, age, type and duration of immunosuppression, infection, microbiological identification, SAPS II and SOFA (24h after admission). Two final models including significant $(\mathrm{p}<0.2)$ and clinically relevant variables were built (one included acute dysfunctions variables and the other did not). The accuracy of the final models and of the physiological scores was calculated using the area under the receiver operating characteristics curve (AU-ROC).

\section{Results}

91 patients were included in the study, aged (mean \pm SD) $59 \pm 15$ years, $54 \%$ were male. Median (IQR) length of stay was 7 (2-10) days. Immunosuppression was due to autoimmune disease in 28 (31\%) patients, solid tumors in $18(20 \%)$, hematological disease in $14(15 \%)$ and solid organ transplant in $26(28 \%)$. Immunosuppressive treatment was corticosteroids in 61 patients (34\%), chemotherapy in 29 (32\%) and other medication in 45 (50\%); 67 patients $(74 \%)$ were under more than one immunosuppressive treatment. Mean \pm SD SAPS II was $52 \pm 21$ and SOFA was $9 \pm 4$. Hospital mortality rate was $48 \%(n=44)$. In the model that included acute dysfunctions, the only independent variable associated with hospital mortality was hematologic dysfunction (SOFA score $\geq 1$ ) [adjusted OR $(95 \% \mathrm{CI})=5.06(1.55-16.46)]$. In the model that did not include acute dysfunctions, hospital mortality was only associated with microbiologic documentation of infection [adjusted OR $(95 \% \mathrm{CI})=3.14$ (1.07-9.19)]. The adjusted OR (95\% CI) for SAPS was 1.035, per point (1.011-1.060) and for SOFA was 1.220, per point (1.071-1.390). The AUROC curve $(95 \% \mathrm{CI})$ for the first model was 0.58 (0.46$0.70), 0.69$ (0.58-0.80) for the second model, 0.68 (0.57$0.79)$ for SAPS II and $0.70(0.59-0.81)$ for SOFA score.

\section{Conclusions}

SAPS II and SOFA did not show good discrimination power to predict hospital mortality in immunosuppressed patients admitted into ICU care. Prospective studies on better discrimination variables are needed for this specific group. 


\section{References}

1. Janssen NM, Karnad DR, Guntupalli KK: Rheumatologic diseases in the intensive care unit: epidemiology, clinical approach, management, and outcome. Crit Care Clin 2002, 18(4):729-748.

2. Cavanna L, Berte R, Bidin L, Anselmi E, Lazzarro A, Moroni CF, et al: Oncologic emergencies secondary to advanced colorectal cancer successfully treated with oxaliplatin/5-fluorouracil/leucovorin: report of three cases. J Chemother 2005, 17(3):334-338.

3. Klouche K, Amigues L, Massanet P, Garrigue V, Delmas S, Szwarc I, et al: Outcome of renal transplant recipients admitted to an intensive care unit: a 10-year cohort study. Transplantation 2009, 87(6):889-895.

doi:10.1186/2197-425X-3-S1-A526

Cite this article as: Medeiros et al:: The accuracy of SAPS II and SOFA

score to predict mortality in immunosuppressed patients admitted in intensive care. Intensive Care Medicine Experimental 2015 3(Suppl 1):A526.

\section{Submit your manuscript to a SpringerOpen ${ }^{\mathcal{O}}$ journal and benefit from:}

- Convenient online submission

- Rigorous peer review

- Immediate publication on acceptance

- Open access: articles freely available online

- High visibility within the field

- Retaining the copyright to your article

Submit your next manuscript at $\gg$ springeropen.com 